\title{
Timing of First Antenatal Care Attendance and Associated Factors among Pregnant Women in Arba Minch Town and Arba Minch District, Gamo Gofa Zone, South Ethiopia
}

\author{
Feleke Gebremeskel, ${ }^{1}$ Yohannes Dibaba, ${ }^{2}$ and Bitiya Admassu ${ }^{2}$ \\ ${ }^{1}$ College of Medicine and Health Sciences, Arba Minch University, P.O. Box 021, Arba Minch, Ethiopia \\ ${ }^{2}$ College of Health Sciences, Jimma University, P.O. Box 378, Jimma, Ethiopia \\ Correspondence should be addressed to Bitiya Admassu; bitiyaa@yahoo.com
}

Received 17 June 2015; Accepted 27 September 2015

Academic Editor: Evelyn O. Talbott

Copyright ( $) 2015$ Feleke Gebremeskel et al. This is an open access article distributed under the Creative Commons Attribution License, which permits unrestricted use, distribution, and reproduction in any medium, provided the original work is properly cited.

\begin{abstract}
Objective. To assess the timing of first antenatal care attendance and associated factors among pregnant women in Arba Minch Town and Arba Minch District, south Ethiopia. Method. Facility based cross-sectional study employing both quantitative and qualitative methods was conducted from February to March, 2014, in Arba Minch Town and Arba Minch District. Data were collected from 409 pregnant women attending antenatal care clinics in nine public health facilities using systematic random sampling. Analysis was done using SPSS version 20. Descriptive statistics and binary and multiple logistic regression analysis were done. Results. The mean (SD \pm ) age of the respondents was $26 \pm 5.5$ years. The mean gestational age at first antenatal care attendance was $5 \pm 1.5$ months. This study indicated that pregnant women with low monthly income ( $\mathrm{AOR}=4.9$, CI: 1.71, 14.08), women who did not receive advise on when to start ANC (AOR = 3, CI: 1.48, 6.24), women with household food insecurity (AOR = 4.66, CI: 1.007, 21.59) and women with unplanned pregnancy $(\mathrm{AOR}=4.49$, CI: $2.16,9.35)$ had higher odds of late antenatal care attendance compared with their counterparts. Conclusions. The study showed that majority of the pregnant women attended late for first antenatal care. Hence, providing health education on the timing of antenatal care is important.
\end{abstract}

\section{Introduction}

Maternal mortality is a major health problem in sub-Saharan Africa. According to the recent estimate by the maternal mortality estimation interagency group, the number of maternal deaths worldwide has declined to 289,000 in 2013 , representing $45 \%$ decline from the 1990 level [1]. About $62 \%$ of these deaths occurred in sub-Saharan Africa where the maternal mortality ratio still stands at 510 deaths per 100,000 live births. Moreover, majority of the countries with the highest maternal mortality are in sub-Saharan Africa, including Ethiopia [1, 2]. In 2011, the maternal mortality ratio in Ethiopia was estimated at 676 deaths per 100,000 live births [3]. Most of these deaths occur unpredictably during labor, delivery, and the immediate postpartum period. Although efforts have been made to achieve the Millennium Development Goal (MDG5) on maternal health to reduce the maternal mortality ratio (MMR) by three-quarters by 2015 , this goal has not been achieved yet. This is mainly because of the low utilization of maternal health services. Quality reproductive and maternal health care throughout pregnancy, childbirth, and the postpartum period can effectively ensure positive health outcomes for women and their children $[1,4,5]$.

Pregnancy is one of the most important periods in the life of a woman, a family, and a society. Antenatal care (ANC) is special care for women during pregnancy through the public health services. The goal of ANC is to prevent health problems in both the fetus and mother and to ensure that each newborn child has a good start [5-7]. World Health Organization (WHO) recommended that pregnant women in developing countries should seek ANC within the first three months of pregnancy. For programme areas in particular, namely, tuberculosis (TB), nutrition, immunization against tetanus, and prophylactic treatment of malaria 
and human immune virus/acquired immune deficiency syndrome (HIV/AIDS) and other sexually transmitted infections (STIs), the antenatal period represents an important opportunity, yet it currently appears to be underexploited $[7,8]$.

Moreover, planning for a safe delivery is an integral part of ANC. Early antenatal care attendance during the first three months of gestation plays a major role in detecting and treating some complications of pregnancy and forms a good basis for appropriate management during delivery and after childbirth. Failure to attend antenatal care early results in the potential for complications during pregnancy, delivery, and puerperium $[6,9]$. However, existing evidence from developing countries including Ethiopia indicates that few women seek antenatal care at early stage of their pregnancy [3, 10, 11]. According to the 2011 Ethiopia Demographic Health Survey, $19 \%$ of women with a live birth in the five years before the survey made four or more ANC visits during their recent pregnancy, while only $11 \%$ made their first ANC visit before the fourth month of pregnancy. The median duration of pregnancy at the first visit was 5.2 months, and urban women made their first ANC visit earlier (4.4 months) than rural women (5.5 months) [3].

Studies have identified several factors that influence the utilization of antenatal care in developing countries, although there are few studies regarding factors affecting the timing of first ANC attendance. These factors include, among others, maternal education, husband's education, availability of health service, cost, household income, women's employment, media exposure, and having a history of obstetric complications [12-15]. Although there is limited evidence, late booking of antenatal care has been associated with young age, premarital status, unwanted pregnancies, high parity, lack of formal education, low socioeconomic status, and ethnicity [16-18]. Unintended pregnancy also had an influence on antenatal care use; this may lead mothers to attend antenatal care late or to not attend at all [10, 19]. The quality of antenatal care might have an influence on utilization of antenatal care, leading to infrequent or late first visits to antenatal care $[18,20-22]$.

Even in the urban areas of Ethiopia, where the health services are physically accessible and available and also maternal health services in public facilities are provided for free, early ANC attendance is still low $[18,23]$. These studies identified several barriers to early ANC attendance. A study carried out in Addis Ababa (Ethiopia) revealed that respondents who received advice on recommended time were more likely to start ANC timely than those who had no information or advise about ANC [18]. Another study in Bahir Dar, Ethiopia, showed that the likelihood of delivering at home was greater among mothers who started attending ANC after 24 weeks of gestation [23]. There were no studies on the magnitude of early ANC initiation and associated factors in southern Ethiopia and in the study area in particular. Late initiation of ANC may lead to undetected or late detection of maternal health problems and subsequently unmanaged complication among pregnant women and thus contributes to maternal mortality. Thus, the aim of this study was to examine factors associated with delay in first ANC attendance.

\section{Methods}

2.1. Study Setting. The study was conducted in Arba Minch Town and Arba Minch District public health facilities, Gamo Gofa Zone, in Southern Ethiopia. Arba Minch is a town located $505 \mathrm{Km}$ away from Addis Ababa and $275 \mathrm{~km}$ south west of Hawassa, capital city of the southern regional state. Facility based cross-sectional study design was employed using quantitative and qualitative methods. The study was carried out among selected pregnant women attending ANC service in public health facilities from February to march, 2014. Pregnant women who attended first ANC visits in other health facilities who were seriously ill and unable to respond were excluded.

2.2. Sample Size and Sampling Technique. Sample size for the study was calculated using single population proportion formula with the following assumptions. Based on findings from a previous study in Bahir Dar (Ethiopia) the proportion of women who start ANC after the fourth month was found to be $59 \%$ [24]. By assuming a margin of error of $5 \%, Z_{\alpha / 2}=$ value for $95 \%$ CI (1.96), proportion $=59 \%$, and nonresponse rate of $10 \%$, a sample size of 409 pregnant women obtained. Then, stratified systematic sampling was employed to select the study participants from each health facility with total of nine public health facilities. The sampling interval $(k=$ $N / n=2$ ) was used in nine public health facilities to select study subjects. The first client was selected by lottery method among the first two ANC service users. Purposive sampling method was used to select ANC providers who have more experience in ANC unit in health facility and health extension workers who are working in the district for qualitative data.

The outcome variable of this study was late first ANC attendance (starting ANC after 16 weeks of gestation), while the independent variables include sociodemographic and economic factors such as age, educational status, occupation, marital status, religion, ethnicity, place of residence, monthly income, and family size; health service related factors such as client satisfaction with ANC services, availability of Health Care Providers, distance of health facility, payment for ANC, waiting time, and presence of resources; maternal factors such as previous use of service, culture, belief, knowledge towards ANC, means of awareness of pregnancy, perceptions on use of early seeking of ANC, advise from significant others, and timing of pregnancy recognition; obstetric related factors such as acceptance of pregnancy by significant others, birth order, type of pregnancy, gravidity, parity, and bad obstetric history (abortion and still birth); and household food insecurity status was considered as independent variable.

2.3. Data Collection. The quantitative data were collected using a structured interview administered questionnaire. The questionnaire was translated to local language and pretested before field work. Nine female nurses, trained for two days, conducted the exit interview with pregnant women. The interviews were carried out in a private and calm environment so as to ensure confidentiality. For participants who did not recall their gestational age, their medical records 
were reviewed on the same day to collect further information on gestational age during their first ANC visit after having consent. Household food security scale was used to measure food security status [25]. For qualitative data open ended interview guide was used for the in-depth interview with pregnant women, ANC clinic workers, and health extension workers. In-depth interview with six pregnant women, four antenatal care providers, and four health extension workers was also carried out in the study area until the information was saturated.

2.4. Data Analysis. Epidata3.1 and SPSS version 20 were used for data entry and analysis, respectively. Frequency distributions of variables of interest were computed to describe the characteristics of the respondents. Binary logistic regression analysis was used to identify variables that are significant with the outcome variable at $p$ value $\leq 0.25$ and those variables were considered for the final model. Finally, multiple logistic analyses were carried out to identify the predictors of late ANC booking. Backward stepwise regression method was used to test the model's fitness. Those variables with $p$ value $\leq 0.05$ with adjusted odds ratio and $95 \%$ confidence interval were considered as statistically significant. The indepth interviews were audio taped, transcribed, translated, and coded into larger themes and categories, analyzed thematically by open code version 3.4 and triangulated with quantitative data.

Ethical clearance was obtained from the Ethical Review Committee of Jimma University. Permission letter and informed verbal consent were obtained from zonal health department. All informants were ensured anonymity and confidentiality, and they gave their informed consent after appropriate explanation of the study objectives and content.

\section{Results}

Four hundred nine pregnant women were interviewed in this study. Out of those $59(14.4 \%)$ were in the age range between 15 and 19 years, 110 (26.9\%) were in the age range between 20 and 24 years, $127(31.1 \%)$ were in the age range between 25 and 29 years, and $81(18.9 \%)$ were in the age range between 30 and 34 years. The mean $( \pm S D)$ age of pregnant women was $26( \pm 5.5)$ years. The ethnic composition of study participants shows that Gamo (76\%) are the dominant group followed by Welaita (10.8). Around $47.2 \%$ and $46.9 \%$ of participants were followers of Orthodox and Protestant religions, respectively. Majority of pregnant women 384 (93.9\%) were married. Regarding educational status, 117 (28.6\%) and 134 (32.8\%) were illiterate and had attended primary school, respectively. Majority of the respondents $(57.2 \%)$ were rural residents. Nearly half of pregnant women (45\%) had monthly income of above 1425 ETB (Table 1).

Thirty-seven percent (37.1\%) of respondents were gravida one, while the rest (62.9\%) were two and above. One hundred seventy-two $(42 \%)$ of respondents were nulliparous and the rest $237(58 \%)$ had one or more children. Sixty-one $(15 \%)$ of respondents had history of at least one abortion.
TABLE 1: Sociodemographic characteristics of pregnant women in Arba Minch Town and Arba Minch District public health facilities, SNNPR, South Ethiopia, March $2014^{1}$.

\begin{tabular}{|c|c|}
\hline Variable $(n=409)$ & $n(\%)$ \\
\hline \multicolumn{2}{|l|}{ Age, year } \\
\hline $15-24$ & $169(41.3)$ \\
\hline $25-34$ & $208(50.9)$ \\
\hline 35 and above & $32(7.8)$ \\
\hline \multicolumn{2}{|l|}{ Ethnicity } \\
\hline Gamo & $311(76.0)$ \\
\hline Welaita & $44(10.8)$ \\
\hline Amhara & $28(6.8)$ \\
\hline Other ${ }^{2}$ & $26(6.4)$ \\
\hline \multicolumn{2}{|l|}{ Religion } \\
\hline Orthodox & $193(47.2)$ \\
\hline Protestant & $192(46.9)$ \\
\hline Other ${ }^{3}$ & $24(5.9)$ \\
\hline \multicolumn{2}{|l|}{ Marital status } \\
\hline Single & $11(2.7)$ \\
\hline Married & $384(93.9)$ \\
\hline Other ${ }^{4}$ & $14(2.4)$ \\
\hline \multicolumn{2}{|l|}{ Occupation } \\
\hline Government employed & 48 (11.7) \\
\hline Self-employed & $59(14.4)$ \\
\hline Housewife & $293(71.6)$ \\
\hline Other $^{5}$ & $9(2.3)$ \\
\hline \multicolumn{2}{|l|}{ Education status } \\
\hline No education & $117(28.6)$ \\
\hline Primary school (1-8) & $134(32.8)$ \\
\hline Secondary school (9-10) & $88(21.5)$ \\
\hline Above secondary school & $70(17.1)$ \\
\hline \multicolumn{2}{|l|}{ Residence } \\
\hline Urban & $175(42.8)$ \\
\hline Rural & $234(57.2)$ \\
\hline \multicolumn{2}{|l|}{ Household income } \\
\hline$<712.5$ Ethiopian birr & $118(28.9)$ \\
\hline 712.5-1425 Ethiopian birr & $107(26.1)$ \\
\hline$>1425$ Ethiopian birr & $184(45.0)$ \\
\hline \multicolumn{2}{|l|}{ Family size } \\
\hline$\leq 4$ & $285(69.7)$ \\
\hline$>4$ & $124(30.3)$ \\
\hline
\end{tabular}

3.1. Timing of First ANC Attendance. Information on timing of first ANC was collected from the women's recall or client's card if they could not remember the exact dates. Accordingly, the proportion of respondents who made their first ANC visit within recommended time (before 16 weeks of gestation) was $17.4 \%$.

Timing of first ANC attendance ranges from 1st month to 9th month during pregnancy. Around thirty percent (29.9) of the pregnant women attended first ANC visits at four 
months of gestation. The mean duration $( \pm \mathrm{SD})$ of first ANC attendance was 5 months $( \pm 1.5)$. Three hundred seventeen (75.5\%) of pregnant women received advice about ANC use from any one before their first ANC visit. Majority of pregnant women $(58 \%)$ received advice from community health workers, followed by husband (24\%). Two hundred eighty-two (89\%) pregnant women reported that they were advised when to start first ANC visit. Among those women who were advised, $47 \%$ were advised before 16 weeks of gestation. In this study, $71.1 \%$ of pregnant women were aware of danger signs during pregnancy. Among those women who told us the danger signs, $53.6 \%$ were aware of all types of danger signs of pregnancy.

\subsection{Past History of ANC Service Utilization. Among two} hundred fifty-seven pregnant women $(62.8 \%)$ who had history of previous pregnancy in their life, $88 \%$ had attended ANC for the previous pregnancy, while the remaining $12 \% \mathrm{did}$ not attend ANC. Regarding the birth order of the women who attended ANC previously, $62 \%$ was first pregnancy, whereas $39 \%$ was second pregnancy. Out of 227 pregnant women who had history of ANC use in previous pregnancy, $34.4 \%$ had their previous ANC visit before 16 weeks of gestation, while the remaining $65.6 \%$ had their first ANC visit at or after 16 weeks of gestation. Fifty-two (52\%) of pregnant women were satisfied with ANC services in terms of staff approach, laboratory service, privacy, waiting time, and service.

3.3. Current Pregnancy and ANC Utilization. Three hundred fifty-nine $(87.8 \%)$ pregnant women reported that they recognized their current pregnancy when they missed menses (monthly period) for one to three months. Two hundred sixty-nine (66\%) pregnant women reported that their pregnancies were planned. Majority of pregnant women (87.3\%) informed their husbands of their pregnancy first before ANC visits. In addition, pregnant women who came to ANC in this time were asked what made them come in the first trimester, second trimester, and third trimester. Among those who booked late, most of them (61\%) became late because they perceived that it is the right time to start, while $(22 \%),(7 \%),(5 \%)$, and $(4.7 \%)$ came because of lack of time, unawareness of pregnancy, learning from previous experience, and unplanned pregnancy.

3.4. Factors Associated with Late First Antenatal Care Attendance. In this study, the factors that were associated with late ANC attendance were low monthly income, receiving advice on when to start ANC visits, household food insecurity, and unplanned pregnancy. The odds of pregnant women with low household monthly income to delay ANC booking were 5 times $(\mathrm{AOR}=4.9, \mathrm{CI}: 1.713,14.076)$ higher compared to their counterparts with high monthly income. Pregnant women who received advice not on recommended time were 3 times ( $\mathrm{AOR}=3$, CI: 1.476, 6.244) more likely to book late for their first ANC as compared to their counterparts who received advice on recommended time. Pregnant women with unplanned pregnancy were 4.5 times $(\mathrm{AOR}=4.49$, CI: 2.162, 9.353) more likely to book late for their first ANC as compared to their counterparts with planned pregnancy. Pregnant women who are living in food-insecure household were around 5 times (AOR $=4.66$, CI: 1.007, 21.589) more likely to be late for first ANC attendance as compared to women with food-secure household (Table 2).

The qualitative study also indicated some reasons why women come late for ANC. One of the health providers stated "...even though most of them knew the right gestation age when to start but they could not go to health facility at early time of pregnancy without feeling of the baby moving in their abdomen and do not want to show their body for health professionals at first trimester of pregnancy by health care provider." This might be due to lack of knowledge and perception on importance of early antenatal care visits.

\section{Discussion}

According to recommendation of World Health Organization (WHO), a pregnant woman needs to start antenatal care in the first trimester of pregnancy. However, a significant proportion of women from developing countries do not start ANC according to the recommendation. This study revealed that $82.6 \%$ of the pregnant women initiated antenatal care at or after four months of gestation. This finding is higher than that in the studies done in Addis Ababa (Ethiopia), Bahir Dar (Ethiopia), Gonder (Ethiopia), and Nigeria [18, 22, 26, 27]. This might be due to sociodemographic, economic, and cultural differences as evidenced by the fact that majority of pregnant women had no education and only attained primary school; more than half of women living in rural areas were housewives as compared to Addis Ababa and northern Ethiopian residents. This study also showed that the mean gestational age at first antenatal care booking is 5 months. This result is consistent with the Ethiopian Demographic and Health Survey report that showed median duration of pregnancy at the first antenatal care booking of 5.2 months [3]. Household income was one of the factors significantly associated with late antenatal care entry in this study. Pregnant women who had low household monthly income were 5 times more likely to book late for their first ANC booking as compared to their counterparts with high monthly income. This result is in line with the study done in Metekel Zone (Ethiopia), Holeta town (Ethiopia), and Uganda [15, 28, 29] Furthermore, several other studies showed that low monthly income is associated with increased odds of underutilizing antennal care services among pregnant mother. This could be because of the fact that better income might increase the ability to pay for health care services, transportation, and other indirect costs. As compared to the proportion of pregnant women with past antenatal care experience before current pregnancy, those pregnant women without past antenatal care experience started ANC later than pregnant women with past experience for first antenatal care. This finding was supported by the study done in Addis Ababa and Uganda [18, 29].

Previous experience of antenatal care utilization might improve the current pattern of antenatal care and timing of first antenatal care visits. However, the difference in this 
TABLE 2: Multiple logistic regression models identifying factors associated with timing of first ANC attendance among pregnant women in Arba Minch Town and Arba Minch District public health facilities, SNNPR, South Ethiopia, March 2014.

\begin{tabular}{|c|c|c|c|c|}
\hline \multirow{2}{*}{ Variables $(n=409)$} & \multicolumn{2}{|c|}{ First ANC attendance } & \multirow{2}{*}{ Crude OR (95\% CI) } & \multirow{2}{*}{ Adjusted OR (95\% CI) } \\
\hline & Attended late & Attended early & & \\
\hline \multicolumn{5}{|l|}{ Place of residence } \\
\hline Rural & 209 & 25 & $2.98(1.75,5.08)$ & $1.30(0.68,2.48)$ \\
\hline $\operatorname{Urban}^{\circledR}$ & 129 & 46 & 1 & 1 \\
\hline \multicolumn{5}{|l|}{ Educational status } \\
\hline No education & 108 & 9 & $3.24(1.55,6.75)$ & $2.1(0.92,4.79)$ \\
\hline Have education ${ }^{\circledR}$ & 230 & 62 & 1 & 1 \\
\hline \multicolumn{5}{|l|}{ Occupational status } \\
\hline Government $^{\circledR}$ & 35 & 13 & 1 & 1 \\
\hline Self-employed & 46 & 13 & $1.32(0.54,3.18)$ & $1.29(0.48,3.41)$ \\
\hline Housewife & 257 & 45 & $2.12(1.04,4.32)$ & $1.45(0.62,3.93)$ \\
\hline \multicolumn{5}{|l|}{ Monthly income } \\
\hline$\leq 712.5 \mathrm{ETB}$ & 113 & 5 & $5.88(2.24,15.43)$ & $4.91(1.72,14.07)^{*}$ \\
\hline $712.5-1425$ ЕТВ & 79 & 28 & $0.73(0.42,1.28)$ & $0.64(0.34,1.18)$ \\
\hline$\geq 1425 \mathrm{ETB}^{\circledR}$ & 146 & 38 & 1 & 1 \\
\hline \multicolumn{5}{|l|}{ Family size of $\mathrm{HH}$} \\
\hline Less than five ${ }^{\circledR}$ & 224 & 61 & 1 & 1 \\
\hline More than five & 114 & 10 & $3.11(1.53,6.28)$ & $1.53(0.68,3.43)$ \\
\hline \multicolumn{5}{|l|}{ Gravida } \\
\hline Primigravida $^{\circledR}$ & 118 & 34 & 1 & 1 \\
\hline Multigravida & 220 & 37 & $1.71(1.99,2.87)$ & $0.85(0.27,2.67)$ \\
\hline \multicolumn{5}{|l|}{ Parity } \\
\hline Parity zero ${ }^{\circledR}$ & 132 & 40 & 1 & 1 \\
\hline Parity one and above & 206 & 31 & $2.02(1.20,3.38)$ & $1.11(0.58,2.07)$ \\
\hline \multicolumn{5}{|l|}{ Number of children died } \\
\hline No children died ${ }^{\circledR}$ & 276 & 68 & 1 & 1 \\
\hline One died and above & 62 & 3 & $5.09(1.55,16.73)$ & $1.41(0.36,5.53)$ \\
\hline \multicolumn{5}{|l|}{ Previous ANC use } \\
\hline $\mathrm{Yes}^{\circledR}$ & 194 & 33 & 1 & 1 \\
\hline No & 144 & 38 & $0.65(0.38,1.09)$ & $1(0.30,3.46)$ \\
\hline \multicolumn{5}{|c|}{ Advised on when to start $(n=280)$} \\
\hline$<4$ months $^{\circledR}$ & 102 & 30 & 1 & 1 \\
\hline$\geq 4$ months & 133 & 15 & $2.61(1.33,5.10)$ & $3.03(1.47,6.24)^{*}$ \\
\hline \multicolumn{5}{|l|}{ Number of ANC visits } \\
\hline Less than four visits & 107 & 12 & $2.27(1.17,4.41)$ & $1.12(0.53,2.43)$ \\
\hline Four and above & 231 & 59 & 1 & 1 \\
\hline \multicolumn{5}{|l|}{ Types of pregnancy } \\
\hline Planned $^{\circledR}$ & 208 & 61 & 1 & 1 \\
\hline Unplanned & 130 & 10 & $3.8(1.88,7.71)$ & $4.49(2.16,9.35)^{*}$ \\
\hline \multicolumn{5}{|l|}{$\mathrm{HH}$ food status } \\
\hline Food-secure ${ }^{\circledR}$ & 296 & 69 & 1 & 1 \\
\hline Food-insecure & 42 & 2 & $4.9(1.15,20.71)$ & $4.66(1.01,21.59)^{*}$ \\
\hline \multicolumn{5}{|l|}{ Satisfaction } \\
\hline High & 166 & 46 & 1 & 1 \\
\hline Low & 172 & 25 & $1.91(1.12,3.24)$ & $1.5(0.83,2.73)$ \\
\hline
\end{tabular}

囚, reference category. Selection criteria in binary logistic regression at $p \leq 0.25$ and ${ }^{*}$ at $p \leq 0.05$ is considered as statistically significant in multiple logistic regression model. OR: odds ratio. 
study was not statistically significant in final model. This could be due to the fact that the pregnant mother thought there is no need to come early for antenatal care if one has no problem with the pregnancy. Majority of respondents reported that they received advice on when to start visits for antenatal care before being started by community health workers. The study showed that pregnant women who did not receive advice on recommended time were 3 times more likely to book late for their first ANC booking as compared to their counterparts who received advice. This was similar to a study done in Addis Ababa that concluded that pregnant women who received advice on advantage of early booking were 2 times more likely to book timely compared to pregnant women who did not receive an advice [18]. A study from Uganda also reported similar finding [29]. Therefore, this study suggests that advising pregnant women when to start first antenatal care attendance helps the women to attend antenatal care early. In this study women whose pregnancy was unplanned were 4.5 times more likely to book late for their first ANC as compared to their counterparts. This finding is in line with the study done in south west Ethiopia which stated that unintended pregnancy was $25 \%$ and $33 \%$ lower to use antenatal care services and receive adequate antenatal care, respectively [10]. Furthermore, studies indicate that unwanted pregnancies strongly associated with late first antenatal care booking or less frequent antenatal care visits, when compared with pregnancy reported as wanted, increased receiving of antenatal care before the sixth month of gestation, respectively $[10,17,30]$.

Our study also examined the relationship between household food security status and timely use of antenatal care. Women from food-insecure households were nearly 5 times more likely to start ANC late as compared to women from food-secure households. In food-insecure situations, as food becomes the first priority, expenditures on other goods and services could also be foregone to spare money for buying food. These conditions might be unsuitable for pregnant women to utilize maternal health services like early antenatal care visits. In line with this, other studies indicate that food insecurity has been associated with poor pregnancy outcomes, reduced number of antenatal care visits, decreased self-rated health status, and change of behavior [31-33]. Qualitative studies showed that foodinsecure pregnant women worry about having enough food to feed themselves, their unborn children, and their family [34].

This study has some limitations. One of the limitations is the fact that pregnant women who attend antenatal care at private health facilities are not included in the study. Moreover, gestational age was determined based on women's reports of their last menstrual period (LMNP). Ultrasound scan to confirm gestational age was not performed; hence, this may have caused inaccuracies in measurement of gestational age. Moreover, this is a facility based cross-sectional study whose findings are not generalized to a general population. As a cross-sectional study, the associations observed between the explanatory variables and the outcome do not show causal relationship.

\section{Conclusions}

The study showed that more than three-fourth of the pregnant women started ANC in study area. Pregnant women's knowledge of importance of antenatal care for the health of mother and fetus was found to be high. Most of the reasons given by pregnant women who attended antenatal care late were due to perception of appropriate time and shortage of time. This study indicated that low monthly income, women who did not receive advice on when to start antenatal care visits, household food insecurity, and unplanned pregnancy were factors associated with late first antenatal care booking. Based on the findings, it is important to provide continuous health education on importance of early antenatal care visits at health facility.

\section{Conflict of Interests}

The authors declare that they have no conflict of interests regarding the publication of this paper.

\section{Authors' Contribution}

Feleke Gebremeskel, Yohannes Dibaba, and Bitiya Admassu conceived and designed the protocol, performed the data collection, contributed for data analysis, and wrote the paper. All authors read and approved the final paper. Feleke Gebremeskel, Yohannes Dibaba, and Bitiya Admassu contributed equally to this work.

\section{Acknowledgments}

It gives the authors a great honor to thank Jimma University for funding the study. The authors would like to thank Arba Minch health facility staffs and all study participants for their valuable time and cooperation in providing the necessary information. The authors thank data collectors for the devotion and quality work during data collection. The work was funded by College of Health Sciences, Jimma University.

\section{References}

[1] WHO, Trends in Maternal mortality 1990-2013, Estimates by WHO,UNICEF, UNFPA, the World Bank, and the United Nations Population Division, World Health Organization, Geneva, Switzerland, 2014.

[2] M. C. Hogan, K. J. Foreman, M. Naghavi et al., "Maternal mortality for 181 countries, 1980-2008: a systematic analysis of progress towards millennium development goal 5," The Lancet, vol. 375, no. 9726, pp. 1609-1623, 2010.

[3] CSA and ICFI, Ethiopia Demographic and Health Survey 2011, Central Statistical Agency, Addis Ababa, Ethiopia; ICF International, Calverton, Md, USA, 2012.

[4] O. M. Campbell and W. J. Graham, "Strategies for reducing maternal mortality: getting on with what works," The Lancet, vol. 368, no. 9543, pp. 1284-1299, 2006.

[5] T. R. Sullivan and J. E. Hirst, "Reducing maternal mortality: a review of progress and evidence-based strategies to achieve 
millennium development goal 5," Health Care for Women International, vol. 32, no. 10, pp. 901-916, 2011.

[6] G. Carroli, C. Rooney, and J. Villar, "How effective is antenatal care in preventing maternal mortality and serious morbidity? An overview of the evidence," Paediatric and Perinatal Epidemiology, vol. 15, supplement 1, pp. 1-42, 2001.

[7] WHO, Antenatal Care in Developing Countries: Promises, Achievements and Missed Opportunities. An Analysis of Trends, Levels and Differentials, 1990-2001, WHO, Geneva, Switzerland, 2003.

[8] WHO, Practical Internal Medicine of Traditional Chinese Medicine, World Health Organization, Department of Reproductive Health and Research, 2001.

[9] WHO, The World Health Report 2005: Make Every Mother and Child Count, World Health Organization, Geneva, Switzerland, 2005.

[10] Y. D. Wado, M. F. Afework, and M. J. Hindin, "Unintended pregnancies and the use of maternal health services in Southwestern Ethiopia," BMC International Health and Human Rights, vol. 13, article 36, 2013.

[11] A. S. Teferra, F. M. Alemu, and S. M. Woldeyohannes, "Institutional delivery service utilization and associated factors among mothers who gave birth in the last 12 months in Sekela District, North West of Ethiopia: a community-based cross sectional study," BMC Pregnancy and Childbirth, vol. 12, article 74, 2012.

[12] B. Simkhada, E. R. Van Teijlingen, M. Porter, and P. Simkhada, "Factors affecting the utilization of antenatal care in developing countries: systematic review of the literature," Journal of Advanced Nursing, vol. 61, no. 3, pp. 244-260, 2008.

[13] Y. Tsegay, T. Gebrehiwot, I. Goicolea, K. Edin, H. Lemma, and M. S. Sebastian, "Determinants of antenatal and delivery care utilization in Tigray region, Ethiopia: a cross-sectional study," International Journal for Equity in Health, vol. 12, article 30, 2013.

[14] T. N. Achia and L. E. Mageto, "Individual and contextual determinants of adequate maternal health care services in Kenya," Women \& Health, vol. 55, no. 2, pp. 203-226, 2015.

[15] K. Birmeta, Y. Dibaba, and D. Woldeyohannes, "Determinants of maternal health care utilization in Holeta town, central Ethiopia," BMC Health Services Research, vol. 13, article 256, 2013.

[16] A. A. Choté, R. J. Hoefman, G. T. Koopmans et al., "Explaining ethnic differences in late antenatal care entry by predisposing, enabling and need factors in the Netherlands. The Generation R Study," Maternal and Child Health Journal, vol. 15, no. 6, pp. 689-699, 2011.

[17] M. A. Magadi, N. J. Madise, and R. N. Rodrigues, "Frequency and timing of antenatal care in Kenya: explaining the variations between women of different communities," Social Science and Medicine, vol. 51, no. 4, pp. 551-561, 2000.

[18] A. Tariku, Y. Melkamu, and Z. Kebede, "Previous utilization of service does not improve timely booking in antenatal care: cross sectional study on timing of antenatal care booking at public health facilities in Addis Ababa," Ethiopian Journal of Health Development, vol. 24, no. 3, pp. 226-233, 2010.

[19] S. Altfeld, A. Handler, D. Burton, and L. Berman, "Wantedness of pregnancy and prenatal health behaviors," Women and Health, vol. 26, no. 4, pp. 29-43, 1997.

[20] E. Kupek, S. Petrou, S. Vause, and M. Maresh, "Clinical, provider and sociodemographic predictors of late initiation of antenatal care in England and Wales," BJOG, vol. 109, no. 3, pp. 265-273, 2002.
[21] J. O. Parkhurst, L. Penn-Kekana, D. Blaauw et al., "Health systems factors influencing maternal health services: a four-country comparison," Health Policy, vol. 73, no. 2, pp. 127-138, 2005.

[22] T. Ejigu, M. Woldie, and Y. Kifle, "Quality of antenatal care services at public health facilities of Bahir-Dar special zone, Northwest Ethiopia," BMC Health Services Research, vol. 13, article 443, 2013.

[23] F. Abebe, Y. Berhane, and B. Girma, "Factors associated with home delivery in Bahirdar, Ethiopia: a case control study," BMC Research Notes, vol. 5, article 653, 2012.

[24] T. Ejigu, M. Woldie, and Y. Kifle, "Quality of antenatal care services at public health facilities of Bahir-Dar special zone, Northwest Ethiopia," BMC Health Services Research, vol. 13, article 443, 2013.

[25] J. Coates, A. Swindale, and P. Bilinsky, Household Food Insecurity Access Scale (HFIAS) for Measurement of Food Access: Indicator Guide, FANTA, USAID, 2007.

[26] A. M. van Eijk, H. M. Bles, F. Odhiambo et al., "Use of antenatal services and delivery care among women in rural western Kenya: a community based survey," Reproductive Health, vol. 3, article 2, 2006.

[27] T. Belayneh, M. Adefris, and G. Andargie, "Previous early antenatal service utilization improves timely booking: crosssectional study at university of Gondar Hospital, northwest Ethiopia," Journal of Pregnancy, vol. 2014, Article ID 132494, 7 pages, 2014.

[28] G. Tura, "Antenatal care service utilization and associated factors in Metekel Zone, Northwest Ethiopia," Ethiopian Journal of Health Sciences, vol. 19, no. 2, pp. 45-48, 2009.

[29] I. Kisuule, D. K. Kaye, F. Najjuka et al., "Timing and reasons for coming late for the first antenatal care visit by pregnant women at Mulago hospital, Kampala Uganda," BMC Pregnancy and Childbirth, vol. 13, article 121, 2013.

[30] C. Marston and J. Cleland, "Do unintended pregnancies carried to term lead to adverse outcomes for mother and child? An assessment in five developing countries," Population Studies, vol. 57, no. 1, pp. 77-93, 2003.

[31] A. E. B. Borders, W. A. Grobman, L. B. Amsden, and J. L. Holl, "Chronic stress and low birth weight neonates in a low-income population of women," Obstetrics and Gynecology, vol. 109, no. 2, pp. 331-338, 2007.

[32] V. S. Tarasuk, "Household food insecurity with hunger is associated with women's food intakes, health and household circumstances," Journal of Nutrition, vol. 131, no. 10, pp. 2670 2676, 2001.

[33] E. Metallinos-Katsaras, K. S. Gorman, P. Wilde, and J. Kallio, "A longitudinal study of WIC participation on household food insecurity," Maternal and Child Health Journal, vol. 15, no. 5, pp. 627-633, 2011.

[34] A. Hromi-Fiedler, A. Bermúdez-Millán, S. Segura-Pérez, G. Damio, and R. Pérez-Escamilla, "Adaptation of the US household food security survey module for low-income pregnant latinas: qualitative phase," Journal of Hunger \& Environmental Nutrition, vol. 4, no. 1, pp. 62-80, 2009. 


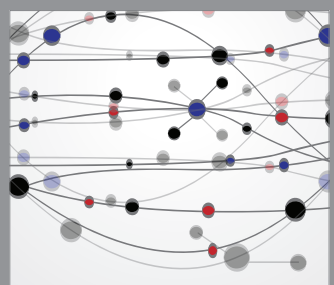

The Scientific World Journal
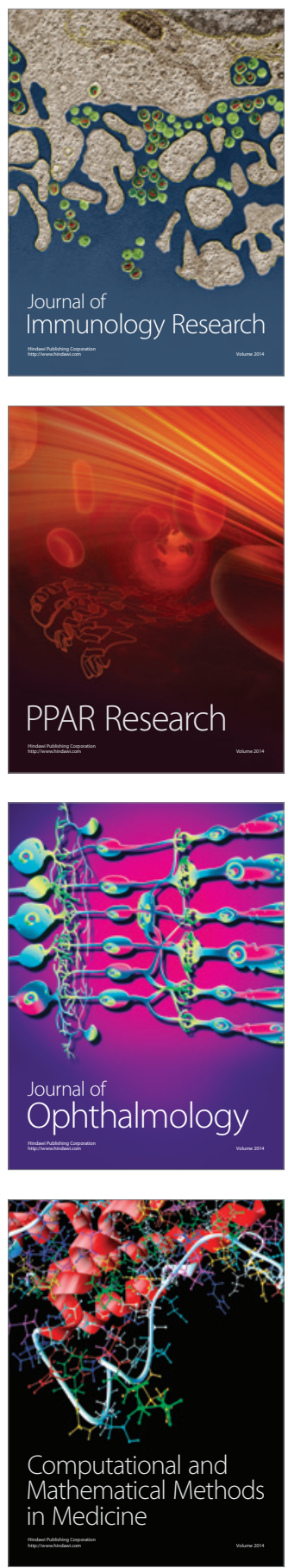

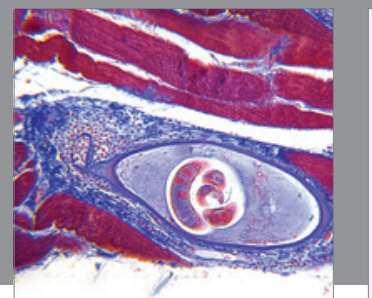

Gastroenterology

Research and Practice
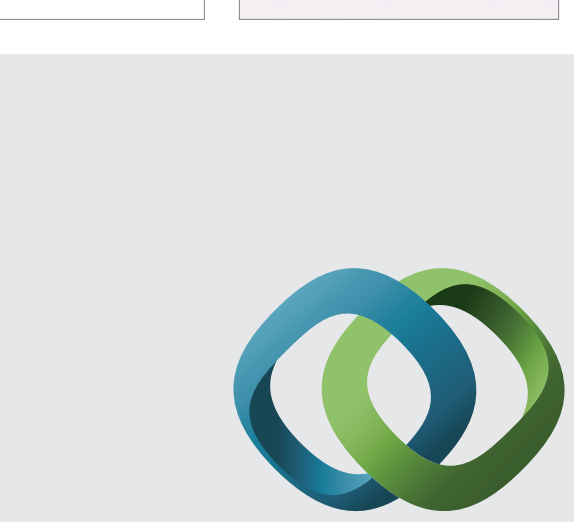

\section{Hindawi}

Submit your manuscripts at

http://www.hindawi.com
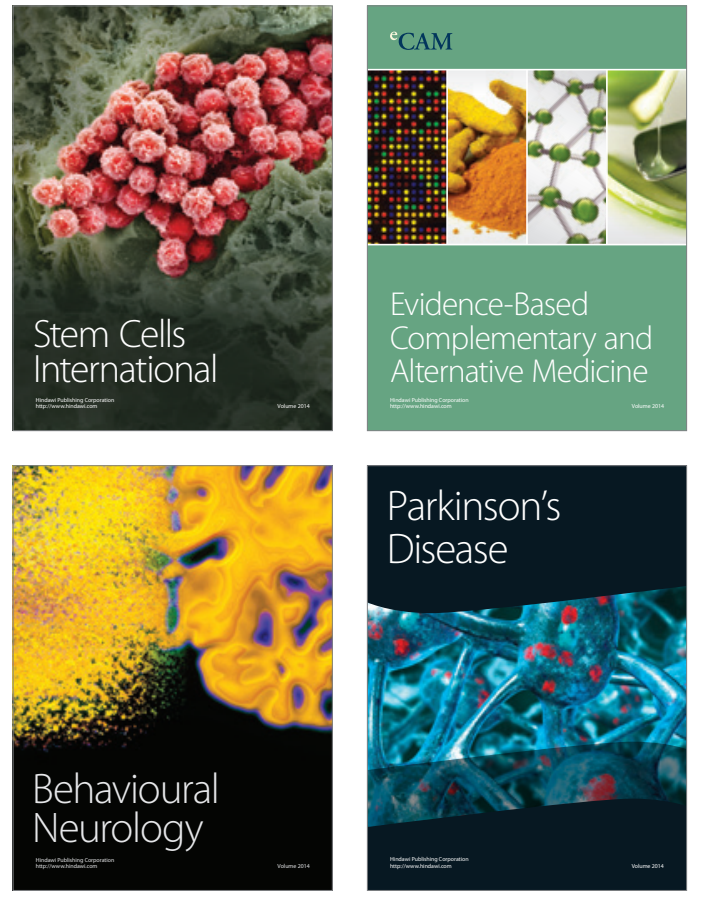
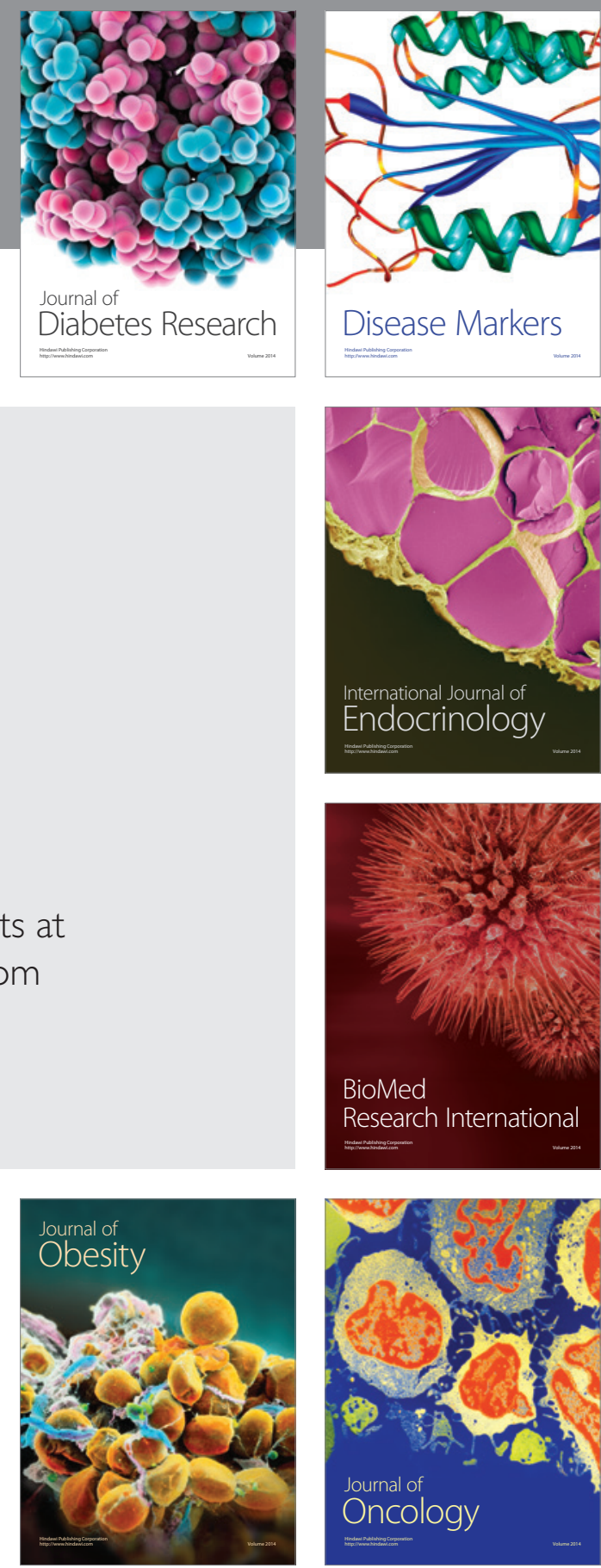

Disease Markers
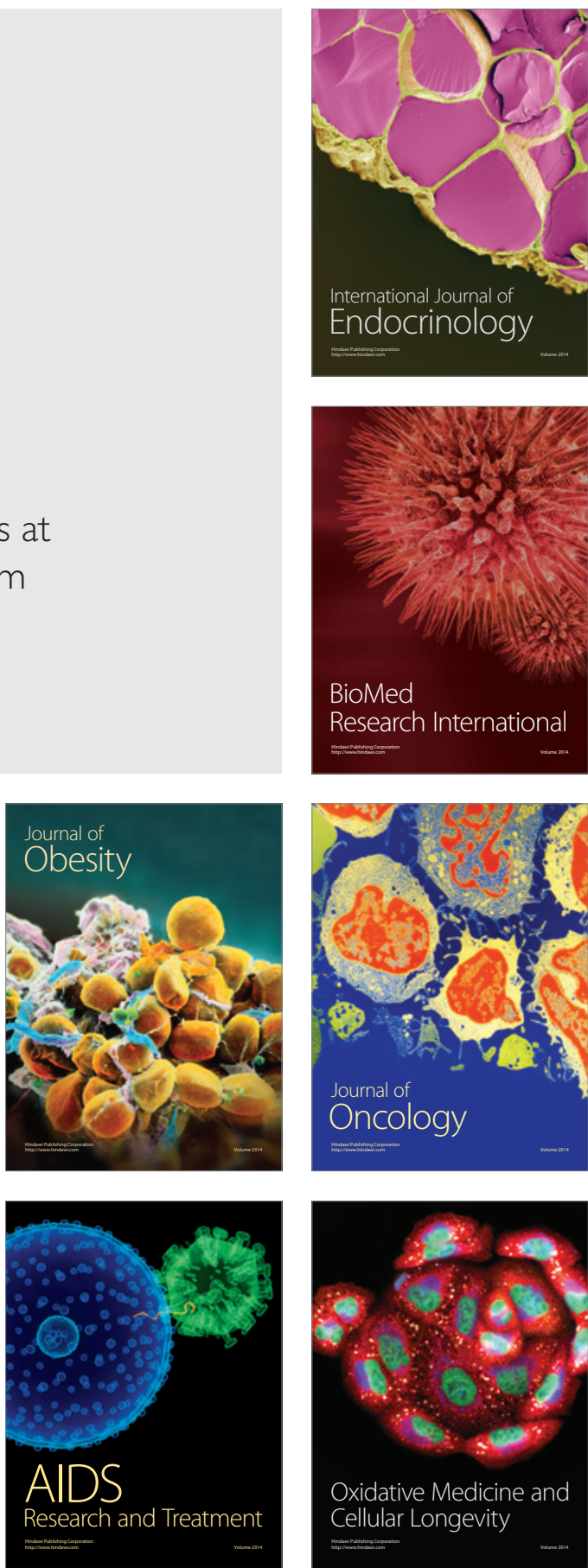